\title{
Celebrating six top achievements in health research
}

\author{
Diane Kelsall MD MEd
}

See related articles by Devereaux and colleagues at www.cmaj.ca/cgi/doi/10.1503/cmaj.110292, by Frank and colleagues at www.cmaj.ca/cgi/doi/10.1503/cmaj.110358, and by Hull at www.cmaj.ca/cgi/doi/10.1503/cmaj.110364.

$\mathrm{T}$ he Canadian Institutes of Health Research (CIHR) and the CMAJ host an annual competition that was launched in 2008 to acknowledge top achievements in health research. The award highlights achievements that have "had a significant impact on health, health care, and health research by improving our understanding of health and human diseases, tackling health challenges, and improving our health system." Achievements in four categories are eligible for the award: biomedical, clinical, health services, and population and public health.

In the second competition (2009-2010), six winners were chosen by an international review committee. Essays by the winners of the three highest-ranking achievements are available at www.cmaj.ca under "Special Reports." Following are synopses of all six winning achievements.

\section{Low-molecular-weight heparin for venous thrombosis}

Who: Dr. Russell D. Hull is professor of hematology, general internal medicine and community health sciences and director of the Thromobosis Research Unit at the University of Calgary.

What: Safe and effective therapies that are appropriate for a wide range of patients with venous thrombosis, including those with cancer, are required. In the early 1990s, Dr. Hull and colleagues began a comprehensive clinical trial program to evaluate alternatives, such as lowmolecular-weight heparin, to treatment with vitamin $\mathrm{K}$ antagonists in venous thrombosis. The findings of these studies showed that there was a safety advantage to the long-term use of lowmolecular-weight heparin by patients with and without cancer, and that there was also a clinical benefit for those with cancer. These studies resulted in several major practice guidelines recommending that low-molecular-weight heparin be the preferred choice for the initial and longterm treatment of patients with cancer who have established venous thromboembolism. Dr. Hull's essay is available at www.cmaj.ca.

\section{Model of care for hip and knee replacement}

Who: Dr. Cyril Frank, Deborah Marshall, Peter Faris and Christopher Smith for the Alberta Bone and Joint Health Institute.

What: Although joint replacement is a proven, cost-effective means of treating severe osteoarthritis in the knee and hip, access to the procedure and consistent quality can be difficult to achieve. In 2004, a collaborative effort, coordinated by the Alberta Bone and Joint Health Institute, began the development of an evidence-based model of care designed to improve access for patients and enhance the quality of service. Following the evaluation of a successful pilot project in 2005-2006, widespread implementation of the model began in Alberta, including an extensive knowledge translation program. Using this work as a foundation, the National Hip and Knee Knowledge Translation Network has been created in Canada, and a national model of care and tool kit for its implementation have been developed. An essay on this project is available at www.cmaj.ca.

\section{Perioperative $\beta$-blockers in noncardiac surgery}

Who: The POISE-1 investigators.

What: Noncardiac surgery is associated with major vascular complications, such as myocardial infarction and stroke. A team of Canadian investigators led a large international trial (Perioperative Ischemic Evaluation-1 [POISE-1]) to evaluate the effects of a $\beta$-blocker in more than 8300 patients undergoing noncardiac surgery. Published in 2008, the POISE-1 study showed a statistically significant increase in death and stroke with a perioperative $\beta$-blocker. The study provided insights as to the mechanism for this increased risk, as more clinically significant hypotension and bradycardia occurred in the treatment group. In addition, the study showed that two-thirds of those with perioperative myocardial infarction did not have ischemic symptoms, likely because most infarctions
Competing interests: None declared.

Correspondence to:

Dr. Diane Kelsall,

diane.kelsall@cmaj.ca

CMAJ 2011. DOI:10.1503 /cmaj.110255 
occurred in the first 48 hours after surgery while patients were receiving high doses of analgesic medications. The results of POISE-1 have been incorporated into several practice guidelines internationally. Building on the knowledge from the POISE-1 trial, the investigators are exploring other interventions, such as low-dose clonidine, to reduce vascular risk in patients undergoing noncardiac surgery. An essay on this project is available at www.cmaj.ca.

\section{Cardiac registry for tracking outcomes in cardiac care}

Who: Dr. William Ghali, Dr. Merril Knudtson, Dr. Michelle Graham, Colleen Norris and Diane Galbraith for the APPROACH team.

What: In 1995, the Alberta Provincial Project for Outcome Assessment in Coronary Heart Disease (APPROACH) was established as a cardiac registry initiative to track the long-term outcomes of all patients undergoing cardiac catheterization in Alberta. In the 15 years since its launch, APPROACH has expanded geographically across Canada and conceptually into managing wait lists and tracking new diagnostic techniques, procedures and other cardiac conditions. The APPROACH team has provided leadership in policy-relevant reporting and nationwide information exchange through interprovincial collaboration, including sharing the APPROACH software system with health regions across the country. Emphasizing knowledge translation processes, educating graduate-level researchers, and publishing multiple papers in major academic journals have contributed to the national and international impact of this project.

\section{Transforming orthopedic care in trauma}

Who: Dr. Mohit Bhandari is the head of the Division of Orthopaedic Surgery at McMaster University, Hamilton, Ontario; Dr. Gordon Guyatt is professor of clinical epidemiology and biostatistics and professor of medicine at McMaster University, Hamilton, Ontario; and Stephen Walter is professor of clinical epidemiology and biostatistics at McMaster University, Hamilton, Ontario.

What: Although trauma is a leading cause of death in the first four decades of life, many studies in fracture care have been single-centre initiatives that are small in size and low in quality. In 1998, this team of researchers from McMaster University set out to collectively improve the way clinical trials are done in fracture care. They focused on open fractures and fractures of the tibial shaft and hip. Their collaboration has expanded to include more than 300 orthopedic surgeons and 70 research coordinators across 238 centres, cul- minating in the completion of the largest trial of fracture care to date and several other randomized trials that address important clinical gaps. Bhandari, Guyatt and Walter have raised the bar for clinical trials in orthopedic trauma care.

\section{Collaboration between infection control and occupational health}

Who: Dr. Elizabeth Bryce is regional medical director for infection control at Vancouver Coastal Health and clinical professor of medicine at the University of British Columbia, Vancouver, British Columbia; Dr. Annalee Yassi is a Canada Research Chair and professor in the College for Interdisciplinary Studies and School of Population and Public Health at the University of British Columbia.

What: Consistent application of the principles of infection control is increasingly important in health care; however, professionals in two key areas - infection control and occupational health - have not traditionally collaborated in working toward this goal. Over the past decade, Bryce and Yassi developed a collaborative research and training team that has produced internationally endorsed guidelines, training products (both online and face-to-face), checklists, research materials, frameworks and a Webbased health information system. Resulting changes to practice and policy in infection control, such as improved use of personal protective equipment for health workers, have occurred in Canada and many other countries, as well as in leading international organizations. Most importantly, Bryce and Yassi have shown that collaboration between occupational health and infection control can be achieved and can result in meaningful outcomes.

\section{Reference}

1. CIHR-CMAJ - Top achievements in health research - 2009 . Ottawa (ON): Canadian Institutes of Health Research; 2009. Available: www.cihr-irsc.gc.ca/e/40251.html (accessed 2011 Feb. 12)

Affiliations: Diane Kelsall is the Deputy Editor, Clinical Practice, CMAJ.

2011 Competition for the CIHR/CMAJ Top Achievements in Health Research

The 2011 competition for the CIHR/CMAJ Top Achievements in Health Research will be launched in the summer of 2011, with a deadline for submissions in the fall of 2011. Details of the competition will be available on the CIHR website (www.cihr-irsc.gc.ca) in June.

Information on the previous winners is available at www.cmaj.ca under "Special Reports." 